\title{
Heidegger e a fundamentação ontológica do design: um paradigma que precede à ciência
}

\section{Heidegger and the ontological foundation of design: a paradigm that precedes science}

\author{
Sérgio Luciano da Silva, Universidade do Estado de Minas Gerais - UEMG \\ sergiolucianosilva@gmail.com
}

\author{
Dijon De Moraes, Universidade do Estado de Minas Gerais - UEMG \\ dijon.moraes@uemg.br
}

\section{Resumo}

O presente artigo é parte de uma investigação mais ampla acerca da natureza do design. Por essa razão, partimos de conclusões anteriores (SILVA; MORAES, 2019), onde sustentamos que o design, enquanto um campo com indeterminações, se mantém, na atualidade, a certa distância do conceito de ciência. No entanto, não entendemos esses componentes indeterminísticos nem esse distanciamento como problemas, pois eles ampliam as possibilidades de conexão deste campo com outras áreas do saber, algumas também com características não científicas, como a arte e a filosofia. O objetivo na etapa atual da pesquisa é encontrar elementos de natureza distinta da epistemológica, que possibilitem compreender os fundamentos do design em sua singularidade. Deste modo, no artigo atual, ao nos afastarmos temporária e intencionalmente da via da ciência, nossa escolha recai sobre a ontologia, por sua anterioridade de fundamentos em relação à diretiva epistemológica. Como interlocutor principal elegemos Martin Heidegger em seu ensaio A origem da obra de arte, apoiados na interpretação de Philippe Lacoue-Labarthe, e deslocamos os desdobramentos de suas reflexões ontológicas da arte para o design, com o subsídio das reflexões de Tomás Maldonado e Vilém Flusser.

Palavras-chave: Teoria e Crítica do Design, Ontologia, Heidegger, Arte, Epistemologia.

\begin{abstract}
This paper is part of a broader investigation into the nature of design. For this reason, we start from the previous conclusions (SILVA; MORAES, 2019), where we maintain that design, as a field with indeterminations, currently remains at a distance from the concept of science. However, we do not face these indeterministic components or distance as problems, as they expand the possibilities of connecting the field to others, some also with non-scientific characteristics, such as art and philosophy. The aim in the current stage of the research is to find elements of a different nature from the epistemological one, which make it possible to understand the fundamentals of design in its uniqueness. Thus, in the current paper, as we temporarily and intentionally move away from the path of science, our choice falls on ontology, due to its previous foundation in relation to the epistemological directive. As the main interlocutor, we chose Martin Heidegger in his essay "The origin of the work of art", supported by Philippe Lacoue-Labarthe's interpretation, and shifted the unfolding of his ontological reflections from art to design, with the support of Tomás Maldonado and Vilém Flusser's considerations.
\end{abstract}

Keywords: Theory and critique of design, Ontology, Heidegger, Art, Epistemology. 


\section{Introdução}

No artigo Subjetividade e objetividade: antinomia kantiana do gosto na arte e no design, (SILVA; MORAES, 2019) defendemos que, na atualidade, não é possível compreender o design enquanto um campo da ciência. Demonstramos que essa conclusão negativa, ao contrário de ser problemática, é o que torna o design um campo singular e com ricas possibilidades de atuação. No entanto, na esfera de fundamentação teórica de um campo, não basta negar uma via de compreensão. É preciso propor outra que estabeleça a sua natureza, sob pena de não se identificar os alicerces que o fundam, limitando seu entendimento. O presente artigo propõe uma trilha ${ }^{1}$ ontológica, revelando elementos que possam garantir o design enquanto disciplina do saber, autônomo como a arte e outros campos que também prescindem de orientação epistemológica. Em outras palavras, o encaminhamento de caráter ontológico que apresentamos aqui procura uma resposta à pergunta que inevitavelmente se faz, quando um campo do saber tem credenciais que não são exigidas pela área da ciência, ou até mesmo recusadas por ela. Essa pergunta é: qual a natureza dos lastros teóricos que fundamentam um campo como o design? A categoria de fundamentação que propomos não pretende excluir ou negligenciar os critérios da régua epistemológica da atualidade, que são, quando necessários, acolhidos pelo design, como defende Gui Bonsiepe ${ }^{2}$. Mas se coloca em um nível precendente no âmbito conceitual e consequentemente mais profundo do que o da epistéme, ou seja, no nível ontológico.

Antes de tratarmos especificamente desse tema é necessário delimitar minimamente o significado da palavra ontologia, que norteará as reflexões deste artigo. Como os demais ramos da filosofia, a ontologia chega à atualidade acumulando diversas acepções derivadas da trajetória histórica do pensamento ocidental, ao passar pelos pensadores que vem se dedicando a esses estudos, dentro da filosofia ou em áreas subsidiadas por ela. Assim, considerando-a em seu caráter geral, ontologia carrega o sentido de reflexão e busca por compreensão da dimensão mais ampla da realidade, e, neste sentido, antecede às questões epistemológicas. Em filosofia é o que denomina-se de investigação sobre "o ser", em que cada ente que compõe a realidade tem sua existência estabelecida, definida e validada por determinado pensador. Por exemplo, se entendermos a arte como um ente da realidade, na concepção platônica, ela, ao contrário da ciência, é mera cópia, imitação (mímesis), não existindo enquanto um campo do conhecimento (SILVA; SILVA, 2013). Consequentemente a arte não é legitimada na ontologia proposta por esse pensador, o que é significativo para a nossa investigação, na medida em que Platão propõe uma cisão e hierarquia entre ciência, técnica e arte que ainda hoje persiste na composição de disciplinas do saber, como o design. Já para a ontologia aristotélica e heideggeriana, como a realidade não se estabelece em separado, em um mundo das ideias, o mundo em que vivemos e agimos, incluindo a arte, tem existência real, com consequências expressivas para o reconhecimento e legitimação de disciplinas não fundadas na pura epistéme, das quais o design faz parte.

Com esse entendimento mínimo sobre o sentido da palavra ontologia, pensemos nas comunidades científicas e tecnológicas da atualidade e nas suas formas de atuação. É a partir dos critérios fixados por tais comunidades que parte considerável dos campos de pesquisa e de

\footnotetext{
1 Utilizamos "trilha", de preferência a "via", reforçando a ideia da ontologia enquanto caminho primordial e originário, como Heidegger propõe em seus escritos.

2 "A atitude de colocar o projeto relacionado com as ciências não deve ser interpretada como um postulado por um design científico ou para transformar design em ciência. [...] O design deve recorrer a conhecimentos científicos quando a temática o exige." (Bonsiepe, 2011, p. 19)
}

Estudos em Design| Revista (online). Rio de Janeiro: v. 28 | n. 2 [2020], p. 6-20| ISSN 1983-196X 
trabalho especializado tem seu status estabelecido, delimitado e regulado, de acordo com os fundamentos teóricos, experimentais e pragmáticos em que se baseiam. Como sabemos, é preciso que perante as comunidades científicas uma determinada disciplina se apresente com diversas credenciais de caráter gnoseológico e epistemológico conectadas à sua prática efetiva, para ser aceita no grupo das ciências e das técnicas modernas (BURTT, 1983), (POPPER, 1975, 1993). Mas essa instância de certificação epistemológica não é exclusiva nem única. Neste artigo, seguiremos por outro caminho de validação.

\section{Tema, objetivo, hipótese e método}

No design ocorre uma confluência e um amálgama entre aspectos estéticos, artísticos, técnicos e epistêmicos que não sucede de forma explícita em campos onde a cientificidade não é questionada (SILVA; MORAES, 2019). Por um lado, o status ontológico do design ainda está por se estabelecer e, por outro, não concordamos com uma hierarquia em que a ciência está no topo do saber, detentora dos critérios de verdade sobre o conhecimento. Diante disso, optamos por buscar em um autor contrário a esse tipo de pensamento conceitos e princípios que contribuem para subsidiar uma fundamentação de caráter distinto no design. Este autor, no nosso entendimento, é Martin Heidegger (1889-1976) e seus argumentos são de base ontológica, sendo um dos filósofos que se insurge contra a tradição cientificista no pensamento ocidental, criticando e expondo as limitações da ciência e da técnica, e contrapondo essas disciplinas à arte.

Este artigo tem um objetivo bem delimitado e um núcleo simples que é seguir o pensamento de Heidegger explorando uma de suas ideias fundamentais: a de que a obra de arte está associada à verdade, em dissonância com a verdade tradicionalmente vinculada à ciência e à técnica. Segundo esse autor, contrariamente ao que se pode correntemente pensar, a arte, como um "modo de produção" distinto dos modos da ciência e da técnica, é capaz de atuar fora de sua esfera, possibilitando uma singular compreensão da essência dos "utensílios", ultrapassando a banalidade de seus usos. Esta proposta nos interessa especialmente pelo fato de que já há algum tempo o design avança e explora territórios que estão muito além da funcionalidade e usabilidade de seus produtos (CARDOSO, 2016). Assim, se aceitarmos os argumentos de Heidegger, é possível orientar suas conclusões acerca dos "utensílios", transpondo-as para o universo do design.

No entanto, tal simplicidade de propósito choca-se com a tarefa de compreender a proposta heideggeriana, complexa não somente pela própria forma em que, sabidamente, este autor apresenta seu discurso, mas também pela natureza intrincada da ontologia, campo distante do senso comum ${ }^{3}$. Devido a isso, tal direcionamento ocupa parte considerável do texto e dos argumentos deste artigo. Mas, acreditamos, as consequências desse esforço tem validade, uma vez que com esses desdobramentos avançamos um pouco na compreensão da natureza do design. Para isso é preciso seguir o pensamento heideggeriano em sua tese de retirada da ciência do foco da busca pela verdade, inserindo a arte neste lugar ontológico privilegiado e extraindo suas consequências para nossa área de interesse. Conforme Heidegger afirma em seu livro A origem da obra de arte:

\footnotetext{
${ }^{3}$ Um exemplo de limitação que o senso comum impõe até aos círculos da reflexão filosófica vem de Pierre Aubenque. Este historiador da filosofia, com o propósito de ressaltar a originalidade de determinados problemas e conceitos filosóficos, como o da ontologia, afirma que: "O problema do ser no sentido da questão O que é o ser? - é o menos natural de todos os problemas, aquele que o senso comum nunca se colocou, aquele que nem a filosofia pré-aristotélica nem a tradição imediatamente posterior se colocaram enquanto tal, aquele que tradições outras que as ocidentais jamais conjecturaram ou abordaram. (AUBENQUE, 2012, p. 22)
}

Estudos em Design| Revista (online). Rio de Janeiro: v. 28 | n. 2 [2020], p. 6 - 20 | ISSN 1983-196X 
A que domínio pertence uma obra? A obra instaura um certo domínio ao qual pertence e que é aberto por ela mesma, porque somente nessa abertura existe o seu ser-obra. Dissemos que, na obra, se realiza o acontecer da verdade e exemplificamos esse fato nos referindo ao quadro de Van Gogh. Tratamos, então, de questionar sobre o sentido da verdade e sobre o seu acontecer. (HEIDEGGER, 1987, p. 228)

$\mathrm{O}$ fato de que o texto de Heidegger explora expressões incomuns e ataca o problema de modo inusitado pode dificultar, em um primeiro momento, o entendimento do essencial: oculta em toda a complexidade do discurso heideggeriano, o que nos interessa, e veremos, é a singular conexão estabelecida por este pensador entre objetos artísticos e objetos úteis. Diante disso, nossa hipótese é de que, na busca por fundamentação, além dos produtos do design (especialmente os utensílios e instrumentos) alcançarem uma compreensão ampliada por esse modo de concepção da realidade, o próprio design pode caminhar em direção a estabelecer seu status ontológico ao lado de outros campos já delimitados e reconhecidos pelas comunidades do saber, independentemente de ser ou não ciência.

Para trilhar esse caminho incluímos no referencial teórico os estudos do filósofo Philippe Lacoue-Labarthe (1996) interpretando tanto a crítica de Heidegger à posição platônica (que defende a ciência como a forma mais apurada e ideal do conhecimento), quanto às possíveis conexões, não declaradas, do pensamento heideggeriano com alguns conceitos de Aristóteles, que neste âmbito discorda de Platão. Corroborando nossos argumentos, na esfera do design, temos em conta algumas considerações de Tomás Maldonado (2012), ao tecer ligações do pensamento de Heidegger com bases teóricas do design e as reflexões de Vilém Flusser (2007) sobre a relevância e autonomia cada vez maior do design ao lado da ciência e da técnica. Metodologicamente, dividimos o artigo em três etapas:

1 Por se tratar de uma longa exposição já detalhada em investigações anteriores (SILVA; SILVA, 2013) e (SILVA, 2019), pressupomos a crítica platônica à arte, ligada ao conceito de mímesis, e apresentamos a oposição de Heidegger a essa concepção.

2 Avançamos para a tese de Heidegger que, segundo Lacoue-Labarthe, reelabora o conceito de mímesis aristotélico de modo não explícito no ensaio A origem da obra de arte, para a sua defesa da relevância ontológica da arte.

3 Operando a partir do registro do conceito heideggeriano de obra de arte, buscamos comprovar nossa hipótese de que compreender o design em bases ontológicas, de modo correlato ao que ocorre com a arte, eleva-o à condição de campo autônomo do saber.

\section{A crítica de Heidegger a Platão: ciência não é a verdade e arte não é cópia da realidade}

Platão, no livro X do diálogo A república (1987), ao criticar a arte tem como alvo a poesia, mas utiliza como um dos exemplos a pintura. A poesia vem simplesmente aderida ao argumento. Se tal é a estratégia platônica para a construção de seu discurso contra a arte produzida no mundo material, os argumentos de Heidegger, no livro A origem da obra de arte (1986, 1987, 2004), tomam o caminho contrário em favor da arte. Numa oposição frontal a Platão, Heidegger busca constituir uma ontologia em que a arte ocupa uma posição privilegiada ao mesmo tempo em que aponta a insuficiência de uma verdade originada em um mundo das ideias separado e distinto do mundo físico em que vivemos. Assim sendo, seu caminho no texto também é inverso. Heidegger inicia com exemplos da pintura e culmina com um de arquitetura que aproximam sua temática de processos de nosso interesse no design:

Estudos em Design| Revista (online). Rio de Janeiro: v. 28 | n. 2 [2020], p. 6 - 20 | ISSN 1983-196X 
Ou será que com a proposição "a arte é o pôr-se-em-obra-da-verdade" se pretende reanimar de novo aquela ideia, em boa hora superada, segundo a qual a arte seja uma imitação e cópia do real? [...] A conformidade com o ente vale, de há muito, como a essência da verdade. Mas será que o que queremos dizer é que o quadro de Van Gogh copia um par de sapatos de camponês que realmente está aí, e é uma obra porque consegue fazê-lo. De modo nenhum. (HEIDEGGER, 2004, p. 28)

Para Heidegger o imitar, no sentido de copiar, não explica o processo constituinte de uma obra de arte. É importante atentar aqui para o exemplo dos sapatos de camponês (que analisaremos em detalhe mais a frente). Ele é crucial para a nossa estratégia de associação com o design, pois conecta quatro pontos: o tema de uma obra de arte, o mundo cotidiano, um exemplo de utensílio e a questão da verdade. Heidegger também mostra outra associação importante para nossa posição ligada ao design, com mais um exemplo, desta vez da arquitetura:

Agora, perguntamos pela questão da verdade em face da obra. Para que nos familiarizemos com o que, na questão, é colocado em questão, é necessário tornar novamente visível o acontecer da verdade na obra. Escolhemos para isso uma obra que não figura entre as obras de arte representativas.

Uma obra de arquitetura - um templo grego — nada reproduz, erguendo-se simplesmente do interior do vale. (HEIDEGGER, 1987, p. 228).

Nas duas citações anteriores, a recusa de Heidegger em pensar a imitação em termos platônicos e direcionadas à concepção aristotélica é confirmada por Lacoue-Labarthe:

[...] já o lembrei antes, Heidegger recusa a palavra; ele afasta com o maior desprezo, um desprezo, aliás, estranhamente platônico e filosófico, toda consideração da "imitação"; e vocês sabem que se o exemplo máximo, em "A Origem da Obra de Arte", é um templo, é porque "o templo não é feito à imagem de nada". Dito isso, o que ele recusa exatamente com esta palavra? Muito explicitamente, mas também muito paradoxalmente, a interpretação platônica da mímesis [...] Ora, isso não impede absolutamente a tese que concerne a arte de ser a reelaboração, jamais abertamente apresentada como tal, mas também nunca totalmente dissimulada, da concepção aristotélica da partição entre phusis e techne $\left.{ }^{4}\right]$, isto é, da concepção ontológica da mímesis [...] (LACOUELABARTHE, 1996, p. 154-155). Negritos nossos.

Essa última citação oferece-nos um olhar diferenciado e uma nova possibilidade tanto porque não abre mão da oposição que Heidegger faz à tradição platônica, e ao mesmo tempo reforça a posição de Lacoue-Labarthe, em consonância com o pensamento aristotélico, de uma "concepção ontológica da mímesis" (SILVA; SILVA, 2013), não entendida como simples imitação ou cópia. Sigamos, portanto, Heidegger em busca desse caminho que pressupõe os conceitos gregos de produção em geral (póiesis), produção da natureza (phýsis) e produção humana (tékhne).

\section{A reelaboração do conceito grego de produção}

$\mathrm{Na}$ antiguidade clássica grega, póiesis é o conceito de produção em sentido mais geral, base para a compreensão de produções específicas como a da natureza, phýsis, e das produções humanas, sejam elas de caráter teórico, epistéme, ou teórico-prático tékhne. Essas produções são os embriões do que posteriormente se desdobram nos conceitos de ciência, técnica e arte na modernidade (Figura 1). Assim, ao retomar esses conceitos na história do pensamento, Heidegger busca compreender a origem daquilo que Villém Flusser identifica como sendo uma

\footnotetext{
${ }^{4}$ Palavras de origem grega costumam ser transliteradas com grafias diversas por autores de diferentes línguas. Por exemplo, $\tau \dot{\varepsilon} \chi v \eta$ aparece nas citações ora como téckne, ora como tékhne e até como techne. Mantivemos a escolha de cada autor nas citações e optamos por unificar somente a nossa grafia. Na transliteração do alfabeto grego para o latino nos apoiamos na Gramática Grega de Antônio Freire, S. J. (FREIRE, 1997) e no método Helleniká (BRANDÃO, SARAIVA, LAGE, 2005).
}

Estudos em Design| Revista (online). Rio de Janeiro: v. 28 | n. 2 [2020], p. 6 - 20 | ISSN 1983-196X 
separação problemática entre campos do saber, e dos quais o design pode assumir na atualidade o relevante papel de "ponte" (FLUSSER, 2007, p. 183) entre áreas cindidas e hierarquizadas.

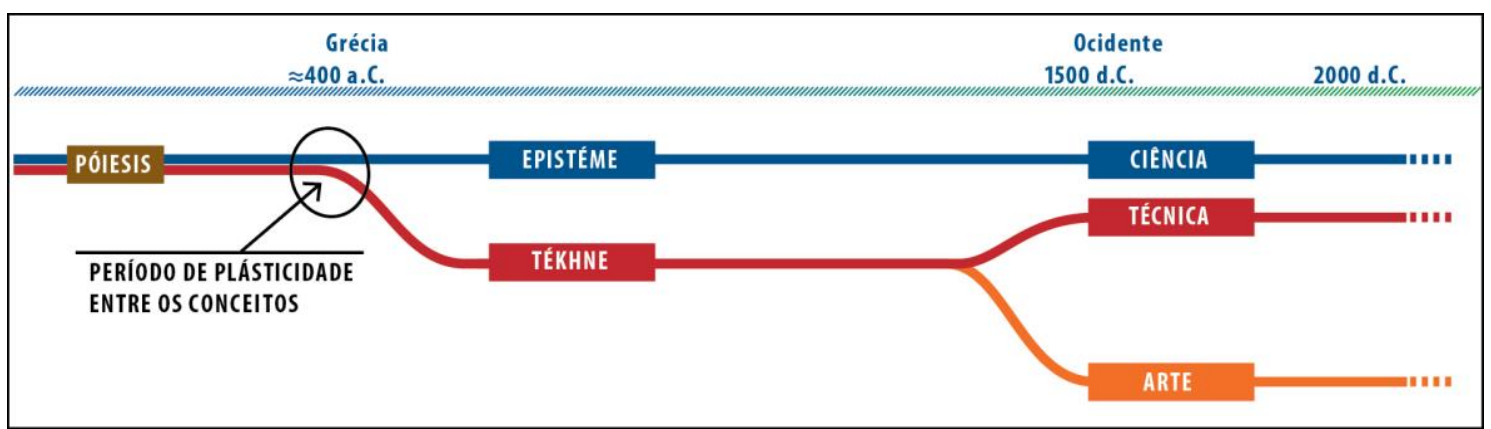

Figura 1. Linha do tempo indicando desdobramento do conceito grego de póiesis (produção) em epistéme (ciência) e tékhne (arte) e posteriormente sua divisão em ciência, técnica e arte em seus sentidos modernos.

A póiesis, ao atuar como força da natureza é delimitada como phýsis, uma modalidade de produção que se faz a partir de si mesma. Um exemplo de phýsis é a transformação de uma semente em árvore, ou como Heidegger afirma em A questão da Técnica "[...] no advento da flor ao florescer [...]" (HEIDEGGER, 2007, p. 379). Póiesis pode ser também tékhne: modalidade de produção que ocorre não a partir de si mesma, mas a partir de outro. Tékhne é arte manual, indústria, ofício e tem por princípio não o fazer, mas principalmente o saber fazer, a habilidade, o método, o artifício, o conhecimento teórico que suporta uma atividade (Figura 2).

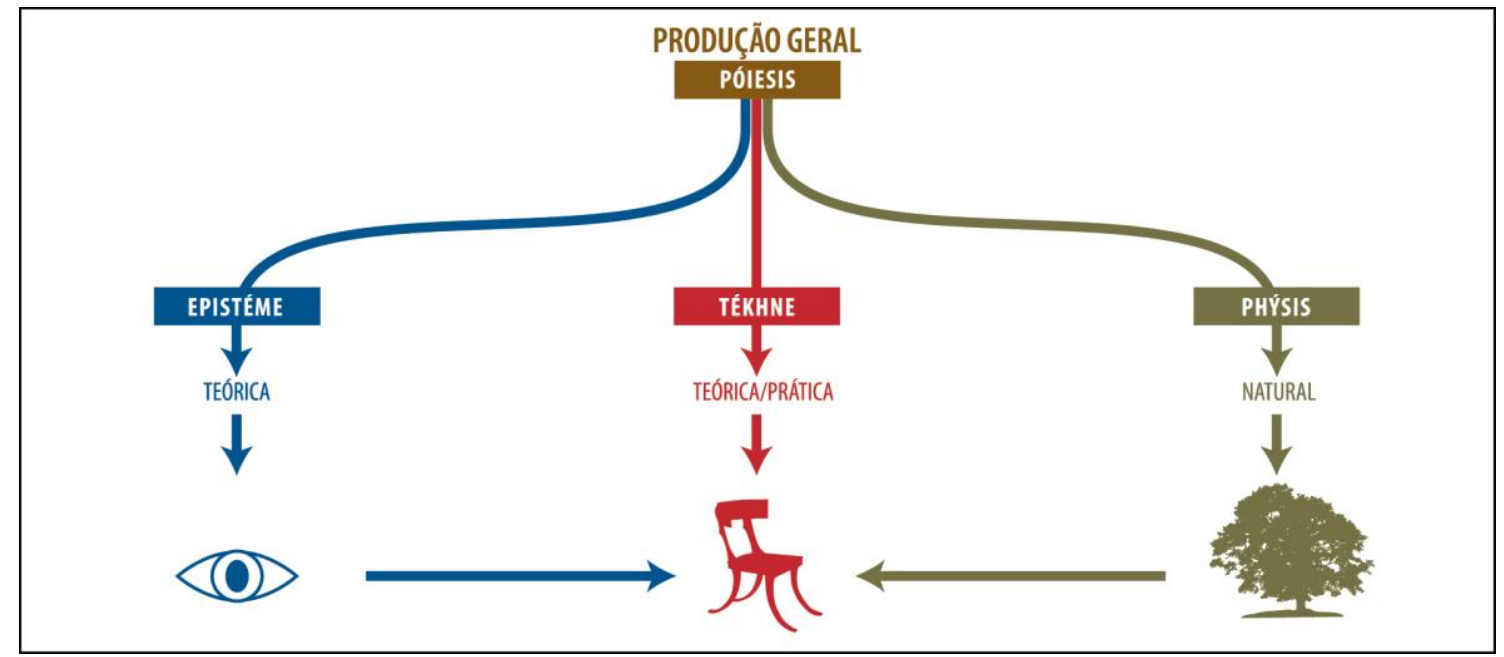

Figura 2. Representação das três categorias de produção e a relação das produções humanas (tékhne e epistéme) com seus fundamentos teóricos.

Lacoue-Labarthe associa o conceito de tékhne ao conceito heideggeriano de mundo e o conceito de phýsis ao de terra, (Figura 3): "[...] a tese que concerne a arte de ser a reelaboração [...] da concepção aristotélica da partição entre phusis e techne, isto é, da concepção ontológica da mímesis: fazer da arte, no combate (o polemos) entre terra e mundo [...]" (LACOUELABARTHE, 1996, p. 155). Nas palavras de Heidegger:

Aquilo em direção ao qual a obra se retrai, permitindo que ela ressurja desse próprio retraimento, chamamos a Terra (die Erde). Ela está sempre eclodindo de sua própria reserva. A terra é o impulso silencioso e infatigável do que é gratuito. Sobre a Terra e na Terra o homem histórico funda a sua morada no mundo. Quando apresenta um mundo, a obra produz (revela) a Terra. Produzir deve ser pensado, aqui, em sentido rigoroso. A obra move e mantém a própria Terra no aberto de um mundo.* A obra tem o poder de fazer a Terra tornar-se Terra. (HEIDEGGER, 1987, p. 234) 


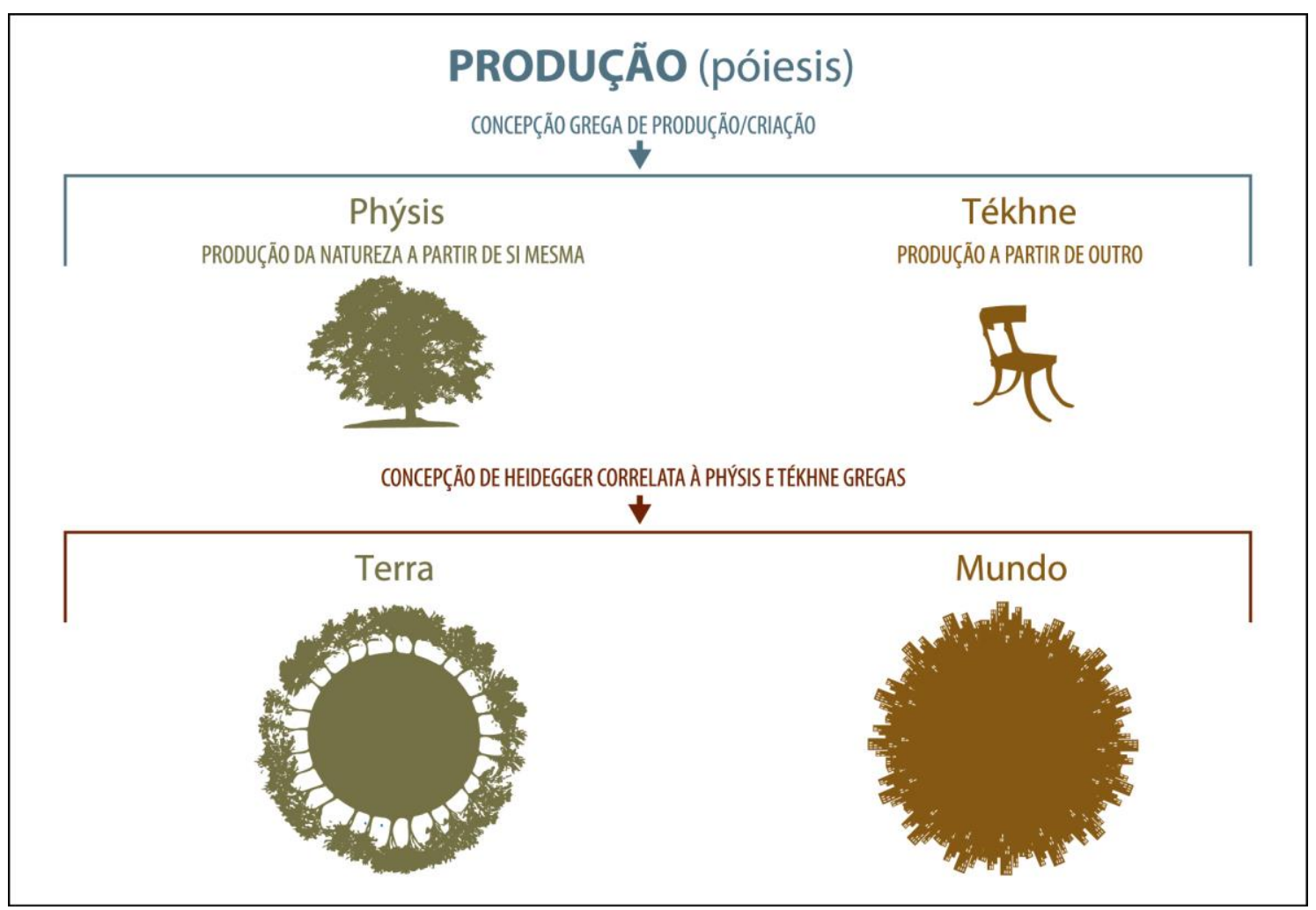

Figura 3. Representação da associação entre os conceitos gregos de Phýsis e Tékhne e os conceitos heideggerianos de Terra e Mundo.

Mesmo que Heidegger, ao trabalhar os conceitos de Terra e Mundo, volte-se apenas para o pensamento grego antigo, sem pensar especificamente em Aristóteles, mas talvez animado pelo pensamento anterior de Heráclito, a interpretação de Lacoue-Labarthe está bem costurada e estabelecida. Na tradução da Revista Kriterion, o asterisco da citação anterior (associado à palavra produzir) envia para a seguinte nota da tradutora Maria José R. Campos, que segue a mesma via interpretativa de Lacoue-Labarthe. Além disso, a tradutora solicita nossa atenção para outra questão, que será direcionada em seguida ao design, e diz respeito ao caráter de não utilidade da obra:

Produzir, executar, significa, em alemão, herstellen. Mas em Heidegger, a palavra possui, aqui, um sentido especial. Além de produzir, significando fazer qualquer coisa de qualquer matéria (produção artesanal), a palavra também pode indicar: manifestar, demonstrar, revelar, o que só acontece na obra de arte. Aí, a matéria, ainda que utilizada, não é jamais utilizada a serviço da utilidade da obra. Na obra de arte, herstellen possui o sentido de trazer à superfície o que está oculto, trazer à luz o sombrio, manifestar o que está em reserva. A palavra possui, em Heidegger, um sentido semelhante ao de herausstellen: colocar para (fora). A obra de arte revela, traz à superfície o que há de mais profundo na realidade material: ela revela a Terra, a physis dos gregos. (HEIDEGGER, 1987, p. 234235) Nota da tradutora.

Assim, considerando a relevância do conceito de póiesis em seus desdobramentos a partir da arte (não concebida como útil), é necessário, na próxima etapa, passarmos em revista o problema da cisão entre ciência, técnica e arte na modernidade. A análise crítica desses três campos, que Heidegger entende como três modos de produção derivados dos conceitos gregos, nos conduz ao final à possibilidade de determinar ontologicamente fundamentos para o design.

\section{Os três modos de produção e sua influência sobre o design}

Tendo em conta a importância do conceito de produção para a constituição do pensamento heideggeriano, torna-se compreensível que esse autor use-o de forma recorrente em suas Estudos em Design| Revista (online). Rio de Janeiro: v. 28 | n. 2 [2020], p. 6 - 20 | ISSN 1983-196X 
reflexões. Na verdade, como veremos, Heidegger entende as categorias de ciência, técnica e arte, em conexão com sua origem no mundo grego e, desta forma, como três modalidades de produção. Como afirma o filósofo Fernando Mendes Pessoa:

Heidegger caracteriza a produção, o pôr-se em obra do real como desencobrimento, com o verbo stellen, "pôr", estabelecendo uma distinção entre essas três modalidades produtivas, a partir do acréscimo de três partículas diferentes a esse verbo: ele caracteriza a produção científica de Vor-stellen, a produção tecnológica de Ge-stellen e a produção artística de Herstellen - termos que, para manter uma analogia na língua portuguesa, poderíamos traduzir como: pro-pôr, com-pôr e ex-pôr (no sentido de produzir, criar). (PESSOA, 2009, p. 195)

\subsection{O modo de produção da ciência}

Em primeiro lugar, para Heidegger a ciência, não em seu sentido epistemológico, mas ontológico - como um dos modos de produção da realidade - é o propor de uma teoria do real. E na modernidade esse "real" se funda na concepção de causa e efeito, noção cara a filósofos e cientistas desde então. O princípio de causalidade é um recurso eficiente na descrição e previsão de fenômenos, o que leva a ciência a partir da modernidade, seduzida por esse poder preditivo, a concentrar-se cada vez mais em questões voltadas para como os eventos se dão ao invés de porque eles ocorrem.

Não é sem razão que Descartes e toda a tradição que o segue, de pensadores, cientistas e teóricos, incluindo na atualidade os do design, a favor ou contra o cartesianismo, reportam-se sempre ao Princípio de Causalidade (seja para reafirmar ou criticar esse conceito) como um ponto nodal para a compreensão da realidade. Maldonado (2012), por exemplo, analisa alguns desdobramentos dessa concepção filosófica no âmbito do design, ao tratar de um dos seus produtos - os óculos —, e argumenta em favor dos conceitos de causa e efeito:

Não se pode desprezar o fato de que os conceitos de causa e de agente têm uma notória e longa tradição no pensamento filosófico. Basta pensar na doutrina aristotélica das 'quatro causas' e nas complexas construções conceituais da escolástica medieval sobre as relações de causa e efeito. E ainda, os sofisticados quebra-cabeças lógico-epistemológicos da moderna filosofia da ciência sobre esse assunto. (MALDONADO, 2012, p. 176).

E Heidegger é categórico acerca da ciência propor um discurso causal sobre o real. Em Ensaios e conferências (Ciência e pensamento do sentido) ele afirma:

A ciência põe o real. E o dispõe a propor-se num conjunto de operações e processamentos, isto é, numa sequiência de causas aduzidas que se podem prever. Desta maneira o real pode ser previsível e tornar-se perseguido em suas conseqüências. É como se assegura do real em sua objetidade [sic]. Desta decorrem domínios de objetos que o tratamento científico pode, então, processar à vontade. (HEIDEGGER, 2012, p. 48)

A crítica de Heidegger se insurge contra toda uma tradição a partir de Platão, que, segundo esse pensador, propõe uma realidade coisificada em que homem e mundo são compreendidos epistemologicamente como separados em sujeito cognoscente e objeto a se conhecer. Em outras palavras, sujeito e objeto, que para Heidegger estão problematicamente cindidos por uma teoria de "causas aduzidas". Se esses argumentos são contundentes ao questionarem as ciências que se estabelecem na esfera dessa dicotomia, por outro lado, pavimentam a base para campos como o design, em que sujeito e subjetividade não podem ser esquecidos ou afastados de objeto e objetividade (SILVA; MORAES, 2019).

\subsection{O modo de produção da técnica}

Estudos em Design| Revista (online). Rio de Janeiro: v. 28 | n. 2 [2020], p. 6 - 20 | ISSN 1983-196X 
Em segundo, a técnica é o compor do real em sua exploração. Ou seja, a técnica, também a partir da modernidade, busca disponibilizar a natureza em seu propósito, dominando-a e explorando-a. Nas palavras de Heidegger:

O desencobrimento que domina a técnica moderna possui, como característica, o pôr no sentido de explorar (Herausforderung). Esta exploração se dá e acontece num múltiplo movimento: a energia escondida na natureza é extraída, o extraído vê-se transformado, o transformado, estocado, o estocado, distribuído, o distribuído, reprocessado. (HEIDEGGER, 2012, p. 20)

Esse segundo modo de produção, de exploração energética do real, segundo Heidegger, é distinto do primeiro e torna o sujeito e o objeto da ciência respectivamente força de trabalho e matéria prima no âmbito da técnica. Maldonado (2012), atento aos questionamentos de Heidegger, aponta que tal preocupação em relação a esse disponibilizar e controlar, que é pretendido pela técnica, já se manisfesta no livro Ser e Tempo (Sein und Zeit), obra anterior à Ciência e pensamento do sentido:

No tom elevado que distingue seu estilo de raciocínio, ele [Heidegger] examina a pretensão (própria e de outros) de querer "controlar espiritualmente a técnica". Em resumo, de querer submetê-la, dominá-la. Em Sein und Zeit (1927), Heidegger já havia analisado as sutis implicações ontológicas do querer "controlar" - sem referir-se explicitamente à técnica quando introduziu a sua famosa distinção entre o modo de ser "utilizável", "prático" (Zuhandenheit) e o modo de estar "presente", "à disposição" (Vorhandensein). (MALDONADO, 2012, p. 154)

Diante da gravidade da crítica de Heidegger aos modos de produção da ciência e da técnica, diversas têm sido as apropriações de seus argumentos em prol de uma maior atenção e precaução aos desdobramentos desses dois campos na atualidade. A discussão sobre a impossibilidade de neutralidade da ciência e da técnica, as consequências nefastas de se separar sujeito e objeto e de ver o homem e a natureza a serviço de um sistema de produção são apenas algumas das diversas questões que apontam para uma dimensão catastrófica de nossa sociedade contemporânea e na qual podemos, sem dúvida, incluir reflexões sobre o papel e a responsabilidade do design. Flusser (2007), por exemplo, segue essa linha de raciocínio em diversos de seus ensaios de filosofia do design, entre os quais se destacam A alavanca contraataca e Sobre a palavra design, que problematizam esses temas, em argumentos que se opõem dialogicamente, mas, de modo perspicaz, não caem no maniqueísmo (SILVA, 2019, p. 87-101).

Mas, por outro lado, pensando em todos os benefícios gerados pela ciência e pela técnica, podemos e devemos recusar esses modos de produção, que por milhares de anos foram se constituindo e garantindo a formação de nossa civilização, levando-nos até onde chegamos? Heidegger tem plena consciência da importância da ciência e da técnica e não as recusa simplesmente. Compreendendo que a ciência e a técnica isoladas ${ }^{5}$ atuam de forma exploratória, voltada para a dominação, conduzindo a uma visão da realidade empobrecida, sua intenção é encontrar um modo de produção que resgate para o ser humano o habitar do mundo em um sentido mais digno e responsável. E esse modo, segundo ele, se encontra na arte.

5 Maldonado também faz uma crítica nessa direção ao afirmar que "Vivemos atualmente em um momento particularmente inovador da longa (e atribulada) história da reflexão sobre a técnica. Constata-se, nas últimas décadas, uma tendência cada vez maior de afastamento daquelas interpretações com viés idealista, que sempre dificultaram as tentativas de se fazer reflexão sobre a técnica. [...] A técnica seria uma realidade autônoma, um sistema fechado, que se desenvolve e se autoexplicaria sem ter de recorrer a fatores exógenos. (MALDONADO, 2012, p. 153) 


\subsection{O modo de produção da arte}

Em terceiro, portanto, Heidegger estabelece a arte como o modo de expor o real em sua liberdade. Em uma passagem de $A$ origem da obra de arte, Heidegger explicita tal produção através da análise de uma pintura de Van Gogh:

Aí estão os sapatos, sejam eles de que tipo forem, com as solas e a pala de couro, percorridas pelas costuras e os pregos. Seu material e sua forma variam de acordo com sua finalidade: trabalhar, dançar, etc... Tudo isto apenas reforça o que já sabemos; o ser do instrumento, enquanto tal, consiste em servir para alguma coisa. Mas será esta a realidade essencial do instrumento? Não devemos explorá-la melhor? A camponesa usa seus sapatos na terra lavrada, pois é aí que os sapatos são o que realmente são. Quanto menos atenção a camponesa dedica a eles em seu trabalho, mais eles se prestam ao serviço de alguma coisa, mais correspondem ao seu ser. Dessa forma, estaremos nos afastando sensivelmente do ser do instrumento, se apenas nos detivermos em sua representação geral, ou na imagem desse quadro, perdida no vazio, onde os sapatos estão desligados da idéia de alguém que os possa estar usando. [...] No entanto, não é só isto...

Observemos as sombras da abertura de seu interior já gasto, onde se esboça a fadiga do andar laborioso, e eis que percebemos os passos rudes, pesados e fatigados do camponês que, sob um vento avassalador, imprime, com sua marcha lenta, grandes e monótonos sulcos na terra lavrada... No couro engordurado pela terra fértil e negra e nas duas solas imóveis, desliza a solidão dos vastos espaços das tardes do campo. No par de sapatos, eclode o secreto apelo da Terra, o cuidado pelo pão de cada dia na promessa do trigo, as auroras glaciais, as tardes enigmáticas à espreita do inverno. Através desse instrumento, o camponês experimenta o exercício pela sobrevivência, da doce espera do filho que retorna à casa, a alegria de sentir a vida, o cuidado de temer a morte. Se o par de sapatos é propriedade da Terra, em sua dignidade, tranqüilidade e segurança, o mundo do camponês o resguarda. É o próprio ser do instrumento que emerge dessa propriedade resguardada, pois, sob esse gesto de proteção, ele repousa em si mesmo. (HEIDEGGER, 1986, p. 205-206)

Foi necessário apresentar essa longa e instigante passagem, com trechos sempre referenciados por comentadores e especialistas de Heidegger, para colocar claramente a relevância da obra de arte, indo além do universo artístico. A obra de arte torna-se subsidiária da compreensão do utensílio, um tipo de "ente" "proposto" pela ciência e "composto" pela técnica, mas cujo entendimento não se esgota em sua utilidade. O caráter poético que Heidegger empresta ao texto demonstra como um filósofo desta envergadura é capaz de atuar no sentido de conduzir o leitor ultrapassando os argumentos da pura reflexão sistemática. Isso porque, para Heidegger, a essência dos instrumentos e utensílios, em seu significado mais profundo e sua dimensão ontológica, se mostra com mais vigor a partir de nossa experiência e fruição da obra de arte.

\section{Uma "promoção ontológica": o design indo além da instrumentalidade e da utilidade}

Para concluir a tese de Heidegger, atentemos a para notável síntese da filósofa Virginia Figueiredo:

É no sentido de uma "promoção ontológica", da qual falava Arthur Danto, ou de uma reversão do platonismo, que tento ler o famoso ensaio de Heidegger. Assim, retomando os resultados da célebre análise aí contida sobre o quadro de Van Gogh, acho que se pode concluir que os sapatos no quadro - dizendo enfaticamente: a imagem pictórica dos sapatos de Van Gogh -, exatamente porque escapam da utilidade, possuem um valor ontológico, muitas vezes superior a qualquer sapato da realidade. São os sapatos do quadro de Van Gogh que nos tornam aptos a, retornando à experiência cotidiana, atribuir algum 
sentido a ela. São os sapatos pictóricos que "salvam" do naufrágio, do afogamento da cotidianidade os sapatos reais. (FIGUEIREDO, 2005, p. 454-455)

As palavras de Figueiredo têm especial relevância para nossa proposta não centrada na utilidade. Do nosso ponto de vista, o discurso heideggeriano e seu propósito podem ser ampliados para a formação de uma consciência do conceito de produção no âmbito do design. A análise deste pensador, que se concentra na arte, mas não permanece somente nela, resgata um modo de compreensão das categorias de objetos que são especificamente utensílios e instrumentos, mas cuja utilidade é apenas um dos seus aspectos constituintes. Ao contrário do que poderia parecer, e isso é de suma importância para nosso argumento, tais objetos, a partir de um olhar proporcionado pelo modo de produção da arte, não se desvalorizam ou se rebaixam, pois não são apenas utilitários forjados pela técnica, subsidiária da ciência. Tais entes explicitam sua dimensão ontológica e até uma "promoção ontológica", como nos lembra Figueiredo sobre a concepção de Arthur Danto (2005), que nos põe em contato com o mundo (tékhne) e com a terra (phýsis) em uma relação que não é nem de conhecimento nem de exploração, ou, em outras palavras, nem de ciência nem de técnica. Neste sentido, as palavras de Maria José R. Campos corroboram a posição heideggeriana de que a arte não somente tem assegurado seu próprio status ontológico como também contribui de modo fundamental para a compreensão dos objetos utilitários:

[...] a arte possui ainda o poder de revelar que as coisas não se esgotam na sua instrumentalidade, pois que sua essência permanece aquém dos nossos projetos utilitários: a arte torna manifesto o ser-instrumento do par de sapatos de camponês pintado por Van Gogh. A verdade das coisas não se fundamenta, pois, senão na significação, no sentido projetado. (HEIDEGGER, 1987, p. 188 - Apresentação)

E se a apreciação das obras de arte nos leva a perceber esses outros significados, o modo ontológico subjacente a ela pode contribuir para nos colocar em uma relação com os objetos do design que não seja somente de mero uso, exploração, acumulação e consumo, mas de "sentido projetado".

\section{Considerações finais}

Diante do percurso empreendido, são necessárias algumas considerações sobre a seara alcançada. Atentos ao contexto mais geral da discussão de cunho ontológico, se nossa sociedade se estabeleceu de modo a dar a primazia ao arcabouço gnoseológico e epistemológico e seus desdobramentos científico-tecnológicos, não podemos nos esquecer que este modo de compreender a realidade tem suas vantagens, mas cobra um alto preço quando não incorpora uma reflexão ontológica. Este é o alerta que permeia o discurso heideggeriano e que filósofos voltados para a fundamentação filosófica do design, como Flusser, sinalizam vigorosamente para o perigo, ousando inclusive colocar esse campo no centro do debate, ao invés da filosofia, da ciência ou da técnica:

Esse é um problema de design: como devem ser as máquinas, para que seu contragolpe não nos cause dor? Ou melhor: como devem ser essas máquinas para que o contragolpe nos faça bem? Como deverão ser os chacais de pedra para que não nos esfarrapem e para que nós mesmos não nos comportemos como chacais? Naturalmente podemos projetá-los de modo a que nos lambam, em vez de morder-nos. Mas queremos realmente ser lambidos? São questões difíceis, porque ninguém sabe de fato como quer ser. No entanto, devemos debater essas questões antes de começarmos a projetar chacais de pedra (ou talvez clones de invertebrados ou quimeras de bactérias). E essas questões são ainda mais interessantes do 
que qualquer chacal de pedra ou qualquer futuro super-humano. Será que o designer estará preparado para colocá-las? (FLUSSER, 2007, p. 49-50)

A metáfora dos chacais de pedra de Flusser é um modo de reflexão que se une à crítica de Heidegger na hipertrofia do utensílio e do instrumento e suas funções e usos empobrecedores da vida humana. E se Flusser não é explícito com relação à trilha ontológica, sua preocupação por uma fundamentação não simplesmente epistemológica do design é clara na citação anterior, ao afirmar a necessidade de debater essas questões previamente aos projetos.

Se Heidegger repete seus argumentos em diversas obras, talvez seja porque ele tem plena consciência do quanto estamos acostumados a uma ideia de verdade apoiada em bases exclusivamente científicas. E se essa ideia é um construto mental, existem modos distintos de entendimento, como ele nos sugere, que podem levar-nos a possibilidades ainda não imaginadas de pensar o mundo, a vida e suas relações com os campos do saber. Assim, retornando à pergunta inicial deste artigo - sobre a natureza dos lastros teóricos que fundamentam o design - acreditamos encontrá-las na filosofia, especialmente na ontologia. Dada a complexidade do design, não é uma resposta simples nem definitiva, pois a trilha ontológica está sendo aberta e não é excludente. Ela se soma aos modos científicos, artísticos e técnicos, e conduz a um campo fértil, até onde sabemos ainda não devidamente explorado pelo design.

No entanto, a partir desse primeiro fundamento, de inspiração heideggeriana, nosso próximo passo na construção desta trilha irá apoiar-se em Karl Popper (1972, 1975, 1993) e Tomás Kuhn (1987), dois autores reconhecidos pelas comunidades científicas por suas teses de fundamentação gnoseológica e epistemológica, mas que defendem paralelamente ao conhecimento científico um espaço autônomo e de saber para campos não científicos como a filosofia ${ }^{6}$, a arte e, no nosso entendimento, também o design. Nesse contexto, como veremos, o lastro ontológico aproxima de modo inusitado design e filosofia (cf. SILVA, 2019, p. 207-212). Daí a relevância de identificarmos e explicitarmos estruturas e procedimentos que são comuns a esses dois campos.

\section{Referências}

ARISTÓTELES. A poética. Tradução, comentários e índices analítico e onomástico Eudoro de Souza. Coleção Os Pensadores, v. 2. São Paulo: Nova Cultural, 1987.

AUBENQUE, Pierre. O problema do ser em Aristóteles: ensaio sobre a problemática aristotélica. Tradução Cristina de Souza Agostini e Dioclézio Domingos Faustino. São Paulo: Paulus, 2012.

BONSIEPE, Gui. Design, cultura e sociedade. São Paulo: Blucher, 2011.

BRANDÃO, Jacyntho José Lins; SARAIVA, Maria Olívia de Quadros; LAGE, Celina Figueiredo. Helleniká: introdução ao grego antigo. Belo Horizonte: Editora UFMG, 2005.

BURTT, Edwin A. As bases metafísicas da ciência moderna. Brasília: UnB, 1983.

6 Se instituições como o CNPq (http://lattes.cnpq.br/web/dgp/arvore-do-conhecimento), ao categorizarem as áreas do conhecimento, colocam a filosofia sob a classe das ciências humanas, não significa que do ponto de vista conceitual essa disciplina não tenha características distintas daquilo que a ciência moderna e contemporânea estabeleceu para si mesma. Guardadas as devidas proporções, o mesmo se aplica ao design, enquanto um campo que o CNPq classifica como ciência social aplicada. 
CARDOSO, Rafael. Design para um mundo complexo. São Paulo: Ubu Editora, 2016.

DANTO, Arthur C. A transfiguração do lugar-comum: uma filosofia da arte. Tradução Vera Pereira. São Paulo: Cosac \& Naify, 2005.

FIGUEIREDO, Virginia. Isto é um cachimbo. Kriterion: Revista do Departamento de Filosofia da Faculdade de Filosofia e Ciências Humanas da UFMG, v. 46, n.112, p. 442 - 457, dez. 2005. Disponivel em: < http://www.scielo.br/pdf/kr/v46n112/v46n112a24.pdf > Acesso em: 07 ago. 2019.

FLUSSER, Vilém. O mundo codificado: por uma filosofia do design e da comunicação. Tradução Raquel Abi-Sâmara. São Paulo: Cosac \& Naify, 2007.

FREIRE, Antônio. Gramática grega. São Paulo: Martins Fontes, 1997.

HEIDEGGER, Martin. A origem da obra de arte. Tradução Maria José R. Campos. Kriterion: Revista do Departamento de Filosofia da Faculdade de Filosofia e Ciências Humanas da UFMG, n. 76, 1986.

HEIDEGGER, Martin. A origem da obra de arte. (continuação) Tradução Maria José R. Campos. Kriterion: Revista do Departamento de Filosofia da Faculdade de Filosofia e Ciências Humanas da UFMG, n. 79/80, 1987.

HEIDEGGER, Martin. A origem da obra de arte. Tradução Maria da Conceição Costa. Lisboa: Edições 70, 2004.

HEIDEGGER, Martin. A questão da técnica. Tradução Marco Aurélio Werle. Scientiae Studia, São Paulo, v.5, n. 3, p. 375 - 398, 2007. Disponível em:

< www.scientiaestudia.org.br/revista/PDF/05_03_05.pdf > Acesso em: 09 jun. 2019.

HEIDEGGER, Martin. Ensaios e conferências. Tradução Emmanuel Carneiro Leão, Gilvan Fogel e Marcia Sá Cavalcante Schuback. Petrópolis: Vozes; Bragança Paulista; Editora Universitária São Francisco, 8a edição, 2012.

KUHN, Thomas S. A estrutura das revoluções científicas. São Paulo: Perspectiva, $2^{\mathrm{a}}$ edição, 1987.

LACOUE-LABARTHE, Philippe. A imitação dos modernos. Org. Virginia de Araujo

Figueiredo e João Camillo Penna. São Paulo: Paz e Terra, 2000.

MALDONADO, Tomás. Cultura, sociedade e técnica. São Paulo: Blucher, 2012.

MALHADAS, Daisi; DEZOTTI, Maria Celeste Consolin; NEVES, Maria Helena de Moura. Dicionário grego-português (DGP). $2^{\mathrm{a}}$ edição. Cotia: Ateliê, 2006-2010. 5 v.

PESSOA, Fernando Mendes. Arte e verdade no pensamento de Heidegger. In: Arqueologias da criação: estudos sobre o processo de criação. Org. Ângela Maria Grando Bezerra e José Cirillo. Belo Horizonte: C/Arte, 2009.

POPPER, Karl R. Conjecturas y refutaciones: el desarrollo del conocimiento científico.

Barcelona: Paidos, 1972.

POPPER, Karl R. Conhecimento objetivo: uma abordagem evolucionária. Belo Horizonte: Itatiaia; São Paulo: Editora Universidade de São Paulo, 1975.

POPPER, Karl R. A lógica da pesquisa científica. São Paulo: Cultrix, 1993.

PLATÃO. A república. Introdução, tradução e notas Maria Helena da Rocha Pereira. $5^{\text {a }}$ edição. Lisboa: Fundação Calouste Gulbenkian, 1987.

Estudos em Design| Revista (online). Rio de Janeiro: v. 28 | n. 2 [2020], p. 6 - 20 | ISSN 1983-196X 
SILVA, Sérgio L.; SILVA, Sérgio A. O Conceito aristotélico de mímesis aplicado ao processo criativo em design. Estudos em Design, Rio de Janeiro, v. 21, n.1, p. 1-14, 2013. Disponível em: <https://estudosemdesign.emnuvens.com.br/design/article/download/107/104> Acesso em: 15 jul. 2020.

SILVA, Sergio. L.; MORAES, Dijon De. Subjetividade e objetividade: antinomia kantiana do gosto na arte e no design. Estudos em Design, Rio de Janeiro: v.27, n. 3, 2019, p. 62 - 78.

Disponível em: < https://estudosemdesign.emnuvens.com.br/design/article/view/773> Acesso em: 28 jul. 2020.

SILVA, Sérgio L. Os fundamentos ontológicos das relações entre design e arte. 2019. $224 \mathrm{f}$. Tese (Doutorado em Design). Programa de Pós-Graduação em Design (PPGD), Universidade do Estado de Minas Gerais, Belo Horizonte, 2019. Disponível em:

<https://sucupira.capes.gov.br/sucupira/public/consultas/coleta/trabalhoConclusao/viewTrabalh oConclusao.jsf?popup=true\&id_trabalho=7672534\#> Acesso em: 15 jul. 2020. 


\section{Sobre os autores}

Sérgio Luciano da Silva < sergiolucianosilva@gmail.com >

Doutorado em Design pela Universidade do Estado de Minas Gerais e Pós-doutorado em andamento pela mesma instituição. Pesquisador do grupo do CNPq Design e Representações Sociais. Suas investigações avançam em duas linhas: Teoria e Crítica do Design - apropria-se de conceitos da Filosofia e da Comunicação para a fundamentação do Design; Estudos da Escrita - une as escritas grega, latina, cirílica e hebraica à caligrafia medieval e renascentista, direcionando-as ao Design Tipográfico Multiescrita.

Dijon De Moraes < dijon.moraes@uemg.br >

PhD em Design pelo Politecnico di Milano, com pós-doutoramento no mesmo instituto. É autor, entre outros, dos livros: Limites do Design; Análise do design brasileiro e Metaprojeto: o design do design. Ocupou por duas vezes o cargo de reitor da Universidade do Estado de Minas Gerais - UEMG; Membro do colegiado do doutorado em design da UEMG e da Università di Bologna - UNIBO (Itália); Instituiu o Centro de Estudos Teoria, Cultura e Pesquisa em Design e a Coleção temática dos Cadernos de Estudos Avançados em Design, ambos na Escola de Design da UEMG. 